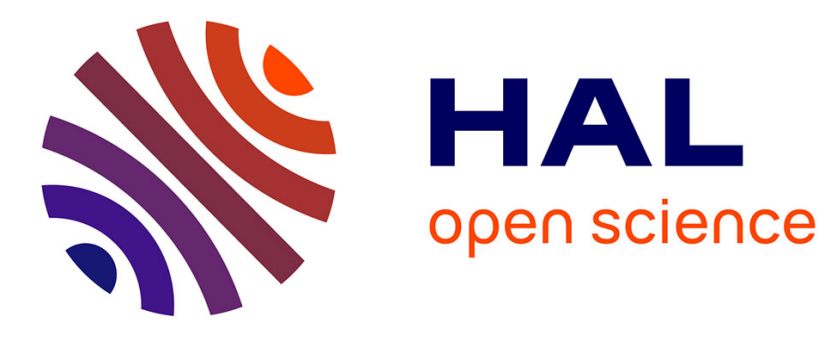

\title{
Modeling of the non-linear mechanical and thermomechanical behavior of 3D carbon/carbon composites based on internal interfaces
}

Adrien Gillard, Guillaume Couégnat, Sylvain Chupin, Gérard Vignoles

\section{To cite this version:}

Adrien Gillard, Guillaume Couégnat, Sylvain Chupin, Gérard Vignoles. Modeling of the non-linear mechanical and thermomechanical behavior of 3D carbon/carbon composites based on internal interfaces. Carbon, 2019, 154, pp.178-191. 10.1016/j.carbon.2019.07.101 . hal-02328597

\section{HAL Id: hal-02328597 \\ https://hal.science/hal-02328597}

Submitted on 20 Dec 2021

HAL is a multi-disciplinary open access archive for the deposit and dissemination of scientific research documents, whether they are published or not. The documents may come from teaching and research institutions in France or abroad, or from public or private research centers.
L'archive ouverte pluridisciplinaire HAL, est destinée au dépôt et à la diffusion de documents scientifiques de niveau recherche, publiés ou non, émanant des établissements d'enseignement et de recherche français ou étrangers, des laboratoires publics ou privés.

\section{(ㄷ)(1) $\$$}

Distributed under a Creative Commons Attribution - NonCommerciall 4.0 International 


\title{
Modeling of the non-linear mechanical and thermomechanical behavior of 3D carbon/carbon composites based on internal interfaces
}

\author{
Adrien P. Gillard ${ }^{\mathrm{a}, \mathrm{b}}$, Guillaume Couégnat ${ }^{\mathrm{c}}$, Sylvain Chupin ${ }^{\mathrm{b}}$, Gerard L. \\ Vignoles ${ }^{\mathrm{a}, *}$ \\ ${ }^{a}$ University of Bordeaux, \\ Laboratoire des Composites ThermoStructuraux (LCTS) \\ UMR 5801: CNRS-Herakles(Safran)-CEA-UBx \\ 3, Allée de La Boétie, 33600 Pessac, France \\ ${ }^{b}$ Dept. of Materials, Direction of Military Applications, \\ French Atomic $\mathcal{G}$ Alternative Energy Agency (CEA/DAM/DMAT), \\ Le Ripault, 37362 Monts, France \\ ${ }^{c} \mathrm{CNRS}$, \\ Laboratoire des Composites ThermoStructuraux (LCTS) \\ UMR 5801: CNRS-Herakles(Safran)-CEA-UBx \\ 3, Allée de La Boétie, 33600 Pessac, France
}

\begin{abstract}
3D Carbon/Carbon composites have an important use in space propulsion and atmospheric re-entry of space objects. We propose a modeling approach for its nonlinear mechanical and thermomechanical behavior based on the introduction of internal interfaces, under the form of cohesive and sliding zones located between the macro-constituents (bundles, matrix pockets). The interface model parameters have been identified from bundle push-out experiments at temperatures from ambient to $1000^{\circ} \mathrm{C}$. The model allowed reproducing successfully a $45^{\circ}$ off-axis tensile test, only with initial damage and interface sliding. The sole incorporation of interface sliding as the only nonlinear phenomenon already allows to successfully reproduce the off-axis behavior. It is also correctly found that the
\end{abstract}

\footnotetext{
*Corresponding author. Tel: (+33) 556844708.

Email address: vinhola@lcts.u-bordeaux.fr (Gerard L. Vignoles)
} 
material has a higher yield limit at high temperature, because its interfaces are closing due to thermal expansion of the bundles. The validity of the model does not encompass yet cases where progressive damage of the bundles occurs, as e.g. in torsion tests.

\section{Introduction}

Carbon/carbon $(\mathrm{C} / \mathrm{C})$ composites are advanced materials designed for hightemperature structural and thermal protection applications [1-3]. Among many other applications, they are used as rocket motor parts and as thermal shields for space objects atmospheric re-entry, due to their unique thermomechanical properties and ablation resistance $[4,5]$. In particular, they have an extremely low thermal expansion coefficient, ensuring resistance to strong thermal shocks. The mechanical and thermomechanical performance of this class of materials is a particularly crucial issue for the design of Thermal Protection Systems (TPS) and, although they have been studied since many years, the need for more accurate models is still strong. For instance, if one of the constituents is changed, or if some processing parameters are altered, it is not possible, on the basis of the current models, to predict how the mechanical and thermomechanical behavior of the material will change, due to a current lack of knowledge on the structure-behavior relationship.

The structure of a typical 3D C/C material [6] is heterogeneous and multiscale. Several thousands of ex-PolyAcryloNitrile (PAN) carbon fibers are linked together into straight, square-shaped or rectangular-shaped yarns with a pitchbased carbon matrix. The yarns are orthogonally fit together into a pattern repeated by translation on a cubic lattice. This macrostructure leads to a network of parallelepipedic macropores, located near each node of the lattice, which are partially filled with ex-pitch carbon matrix and are called matrix pockets. After 
weaving and matrix infiltration, the composite has been graphitized. Fig. 1 is a sketch of the composite architecture. Other yarn arrangements have been designed in order to increase the number of maximal stiffness directions.

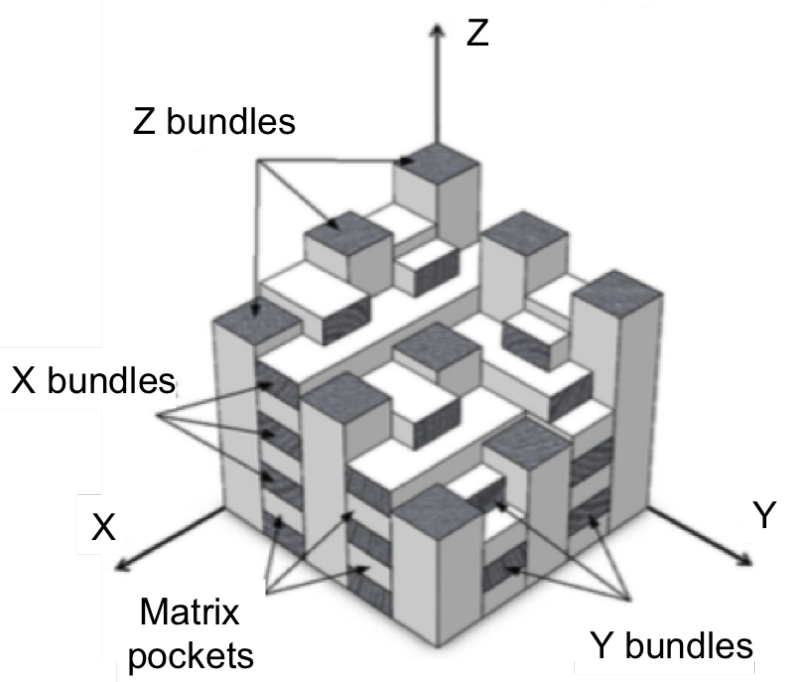

Figure 1: Structure and mesoscale constituents of a 3D C/C composite.

The mechanical behavior of such a type of material has been investigated as soon as in 1976 by Perry and Adams [7], who followed its evolution as a function of the number of graphitization cycles. Yarn/matrix decohesions and intra-yarn crack formation were evidenced. Later on, many other ambient temperature tests have been performed $[6,8-10]$, showing a quasi-linear, perfectly brittle behavior in tension or compression along the yarn directions, whereas $45^{\circ}$ off-axis tensile tests, trisecting direction compression tests and Z-axis torsion tests revealed a markedly non-linear response, due to progressive damage. Similar works have been carried out on variations of the same material [11-13]; characterizations of the material after tests have highlighted the important role of interfaces between adjacent yarns and between yarns and pockets, where debonding and sliding have been evidenced. Such phenomena were confirmed by examination of failure sur- 
faces $[12,14]$. High-temperature tests $[12]$ revealed that the elastic modulus remains unchanged with temperature at least up to $1200^{\circ} \mathrm{C}$. This is consistent with the fact that the material has suffered a much higher graphitization temperature; therefore it was expected that the constituents would remain stable, at least up to the beginning of creep, around $1600^{\circ} \mathrm{C}$ [15]. There is also an appreciable increase of the yield limit of the material in off-axis directions as temperature increases. The closing of the interfaces due to thermal expansion has been invoked to explain this fact $[16,17]$.

The principal mesoscale constituents (yarns, matrix pockets) have been characterized individually $[6,8,9,17]$ : yarns have been tested in tension, torsion and flexion; they display a brittle behavior, whereas the matrix pockets are much less stiff and display appreciable progressive damage before final failure. The individual fibers have also been characterized [17-19], with values matching approximately the manufacturer's data [20]. The very anisotropic elastic and brittle failure properties of the fibers are believed to be responsible for the similar behavior of the yarns.

Since the importance the interfaces has been singled out, specific characterizations have been performed on inter-bundle interfaces, mostly by push-out or pull-out experiments [17, 21-24], including high-temperature testing. As the interfaces are already partially open at room temperature, their behavior is only driven by sliding. As a consequence, typical push-out curves show a first elastic part followed by a yield plateau. This plateau has been attributed to the roughness of the yarns surfaces on each side of the interfaces. It has been shown that increasing temperature induces a higher yield strength and a higher friction plateau of the interfaces. This has been interpreted as the consequence of the partial closure of the interfaces due to the heat expansion of the neighboring yarns. Cracks and voids in the material were imaged at room temperature by X-ray Computed To- 
mography (CT) [25], in an attempt to quantify the thickness of the gaps between yarns.

Modeling of the material behavior has started with phenomenological behavior models, containing ad hoc plasticity laws [6, 9, 10]; other mesoscale models dealing with failure and thermal expansion [16] have been produced. However, these models are not capable of anticipating the effect of changing one of the constituents in the composite. Then, meso-macro approaches have been developed, in which the effective behavior of a Representative Unit Cell (RUC) is obtained numerically by Finite Element (FE) computations, featuring cohesive elements to describe the interfaces [13]. More recent numerical efforts have focused on the simulation of room temperature push-out tests $[24,26]$ and on the computation of elastic properties from 3D X-ray CT images of the material [27]. These imagebased numerical simulations have the potential of being predictive in the case of a change of a constituent; however, their authors have not applied them to the prediction of off-axis behavior or of thermal expansion.

Following the guidelines of these previous studies, the objectives of the present work are the derivation of a multi-scale thermomechanical behavior model, based on the knowledge of the individual behavior of the constituents and of the interfaces, at ambient and high temperatures, and to validate this model against all possible thermomechanical test data available. The first part of the documentpaper will describe the construction of the model, including the procedures for the identification of parameters. Then, validation tests will be shown; finally, the comparison between model simulations and actual experimental data for non-linear mechanical behavior will be carried out and the performances of the modeling approach will be discussed. 


\section{Model setup}

The model has been built following principles explained in previous literature $[13,24,26,27]$. The numerical resolution domain encompasses a large enough volume of the material to be representative - in some cases, the whole samples tested experimentally may fit in the simulation domain. An ad hoc interfacial model has been designed in order to account for the specific behavior of the interfaces. In this section we will describe first the construction of the model mesh and element laws, then address the question of identifying the interfacial laws and parameters, before going to validations of the models with respect to in-axis elasticity and thermal expansion.

\subsection{Domain mesh and elements}

Fig. 2 is a snapshot of a typical 3D FE mesh used for the simulations. All volume elements are tetrahedral and surface elements triangular. The Z-yarns have $800 \times 800 \mu \mathrm{m}^{2}$ sections whereas the $\mathrm{X}$ - and Y-direction yarns are $400 \times 800 \mu \mathrm{m}^{2}$. By construction, this material is designed to contain $75 \%$ vol. yarns and $25 \%$ vol. matrix pockets. Experimentally, it has been found to contain $10.8 \% \pm 0.1 \%$ vol. of pores. Several meshes have been produced, for the simulation of various tests. After creation of the ideal geometries of the vertical and horizontal yarns and of the matrix blocks, a first Delaunay triangulation of the interfaces is achieved using the Triangle software [28] at all boundaries between all constituents, then the inner volumes are meshed with tetrahedra using the triangular meshes of the interfaces as constraints, using the TetGen software [29]. Mesh refinement controls helped maintaining a minimal resolution of $100 \mu \mathrm{m}$ per triangle edge while keeping the total number of element inferior to 200,000. For sake of simplification, the inner pores of the matrix pockets have not been meshed. 


\subsection{Bulk constituents properties}

The bulk elastic properties of the constituents are extremely difficult to obtain experimentally. First, we collected them from past studies on similar materials [8, 9]; they are gathered in Table 1. Instead of performing difficult and poorly reliable tests on our materials, we have chosen to re-identify them a posteriori using our model, composite materials mechanical behavior data, with data of Table 1 as an initial guess. This procedure is further discussed in section 2.4. The properties are considered constant up to $1300 \mathrm{~K}$, as supported by experimental data reported in previous works [15]. No damage or creep has been considered, since the focus is set on the role of interfaces. The heat expansion of the constituents has been given as functions of temperature on the basis of experimental data acquired at our lab for the yarns and for the matrix pockets (Setaram Setsys 2400 Thermo-Mechanical Analysis (TMA) apparatus with a $5^{\circ} \mathrm{C} / \mathrm{min}$ heating rate between $25^{\circ} \mathrm{C}$ and $1200^{\circ} \mathrm{C}$; they are plotted in Fig. 3. Pure ex-pitch matrix cubic samples (6 mm edge size) were cut with a diamond-paste chainsaw and polished before testing. Bundles were prepared by cutting slices slightly larger than one bundle thickness from the composite material, the bundles were manually extracted from the slices using a razor blade and cleaned. These bundles have lengths between 50 and $100 \mathrm{~mm}$. For the longitudinal TMA a single bundle with length $20 \mathrm{~mm}$ sufficed, whereas in transverse (radial) direction the setup was more elaborate: the bundles were laid on each other in a "log heap" arrangement. Five layers of 10-mm bundles were stacked at $90^{\circ}$ with respect to each other for this arrangement. 


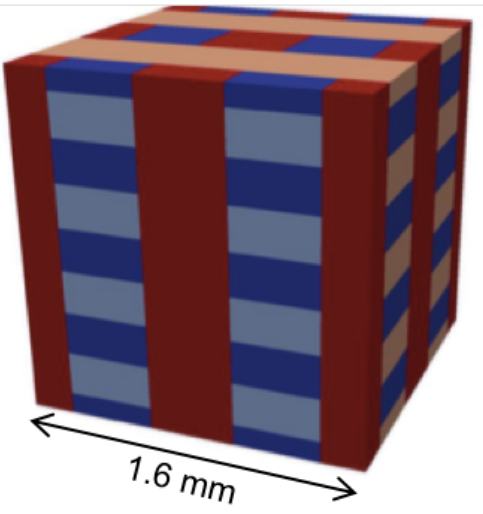

A

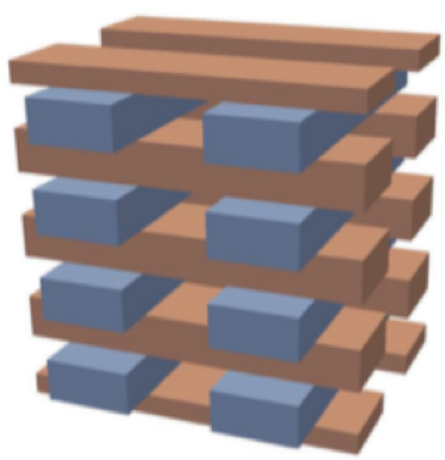

C

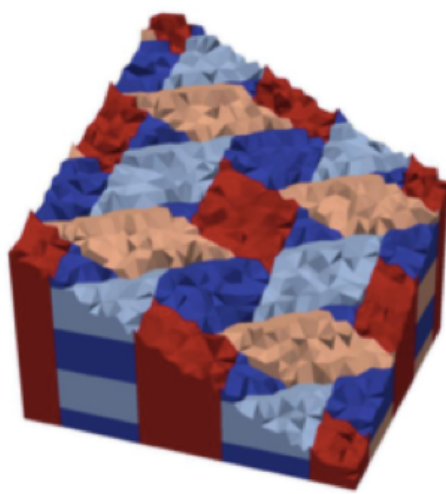

B
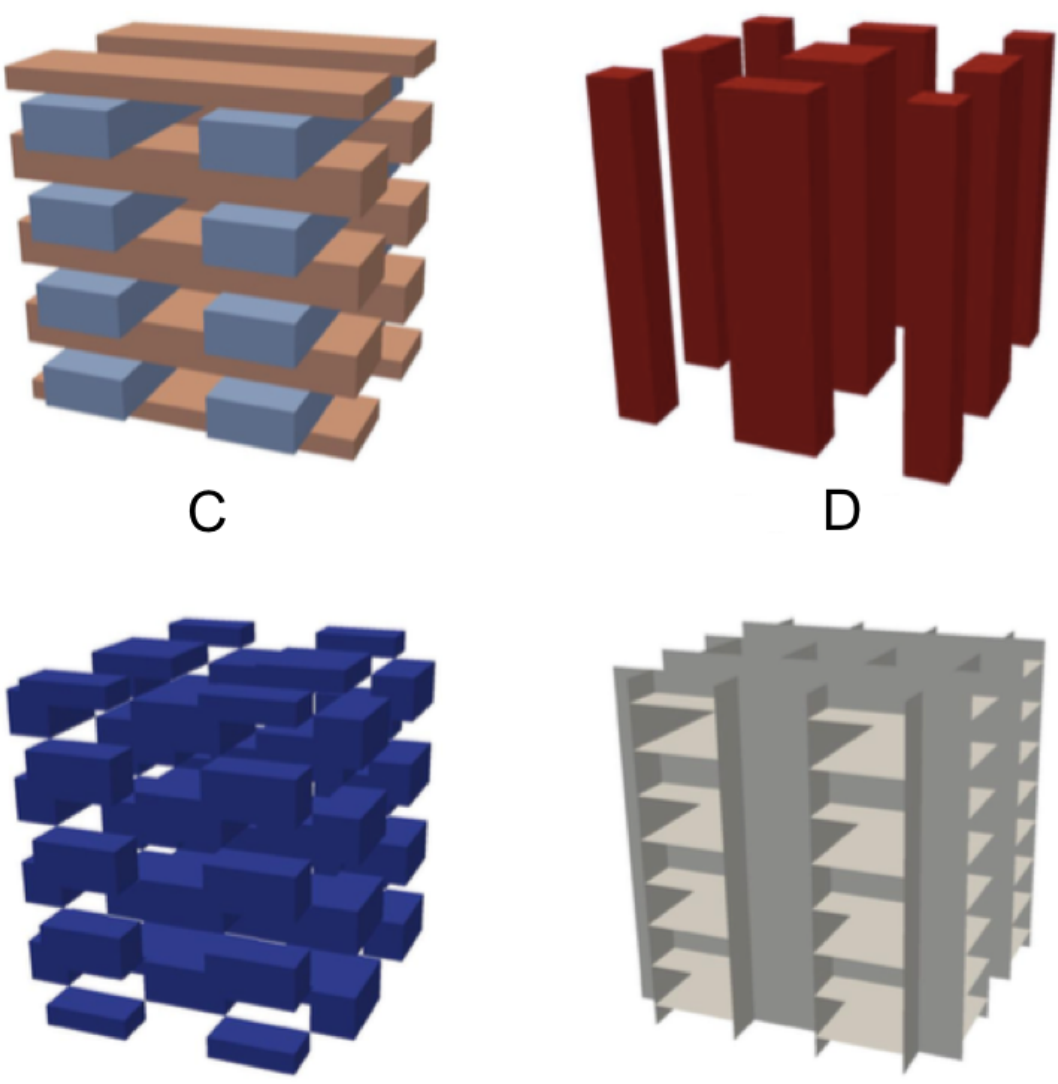

E

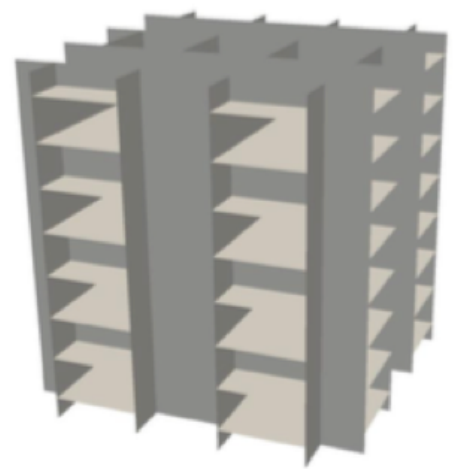

F

Figure 2: Example of a mesh of a resolution domain. A : Full mesh, B : Oblique slice view, C : X and Y-direction yarns, D : Z-direction yarns, E : Matrix pockets, F : mesoscale interfaces. 


\begin{tabular}{lcccccc}
\hline Constituent & \multicolumn{2}{c}{ Young's modulus } & \multicolumn{2}{c}{ Poisson coefficient } & \multicolumn{2}{c}{ Shear modulus } \\
& $E_{L}$ & $E_{T}$ & $v_{L T}$ & $v_{T T}$ & $G_{L T}$ & $G_{T T}$ \\
\hline Yarn & $484 \mathrm{GPa}^{*}$ & $6.0 \mathrm{GPa}$ & 0.25 & 0.45 & $1.70 \mathrm{GPa}^{*}$ & $2.10 \mathrm{GPa}$ \\
Matrix & $3.6 \mathrm{GPa}$ & & 0.15 & \multicolumn{2}{c}{$2.0 \mathrm{GPa}$} \\
\hline
\end{tabular}

Table 1: Bulk mechanical properties of the material mesoscale constituents $[8,9] . L$ means "Longitudinal", $T$ is "Transverse". Properties measured directly from experiments are marked by asterisks; the other values have been calibrated using a mesoscale model.

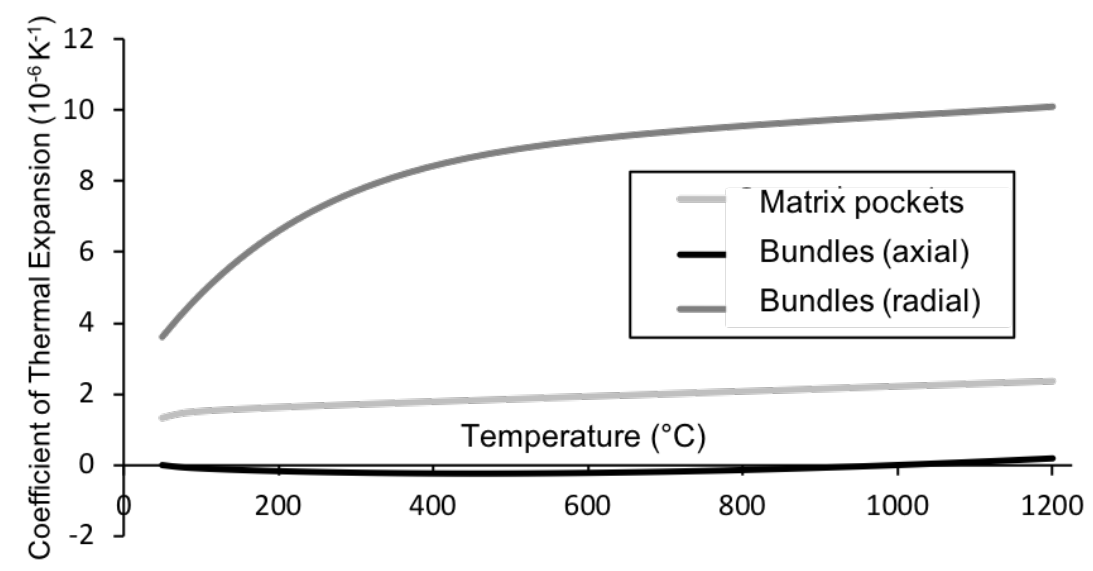

Figure 3: Thermal expansion laws for the mesoscale constituents as a function of temperature, obtained from TMA measurements.

\subsection{Interface elements and identification of interface laws}

Before describing the selected choice for interface laws, we will briefly recall some experimental results; in the end of this section the identification of the parameters will be described in detail.

\subsubsection{Available experimental data}

As said before, most characterizations of the interfaces have been made by means of push-out and pull-out experiments. In the frame of the present study, 
new relevant experimental data has been acquired thanks to a custom high-temperature push-out device [30]. Push-out tests were performed on $\mathrm{X} / \mathrm{Y}$ and $\mathrm{Z}$ yarns and on $200 \mu \mathrm{m}$ yarns, from room temperature up to $1000^{\circ} \mathrm{C}$. The exerted force was recorded as a function of the vertical displacement of the actuator; after setup compliance corrections, displacement and force were converted into relative displacement (displacement to thickness ratio) and stress (force to yarn external surface ratio). Doing this, results for all sample thicknesses could be compared. The push-out tests featured three steps: $i$ ) an elastic loading, mostly reversible, due to the sample bending; ii) an unlocking effect, breaking the few binding areas and clearing debris, marked with a stress peak; iii) a sliding with friction marked with a slow decrease of stress. Fig. 4A summarizes the experimental results obtained at ambient temperature $[30,31]$. Curves obtained at higher temperatures show similar behavior but with a higher shear stress for the same dimensionless displacement, i.e. a higher friction coefficient, as shown in Fig. 4B. The samples were analyzed post mortem on their surfaces and along transverse sections, as illustrated in Fig. 5, and the interfaces between yarns have been characterized by SEM in back-scattered electron mode. Fig. 6 displays lateral and front views of such an interface before push-out. What appears clearly from these observations is that the interface is already initially open, but very rough and containing debris: as a consequence, they can be considered as sliding interfaces even though they are open. When temperature increases, they are progressively closed, as evidenced experimentally by in-situ SEM imaging [17], and the minimal stress required to start sliding as well as the friction coefficient also increase. Previous investigations by Aoki et al. have described a linear dependence of the threshold stress to temperature; accordingly, in the present work, we will assume that all the linear evolution is due to sliding. 

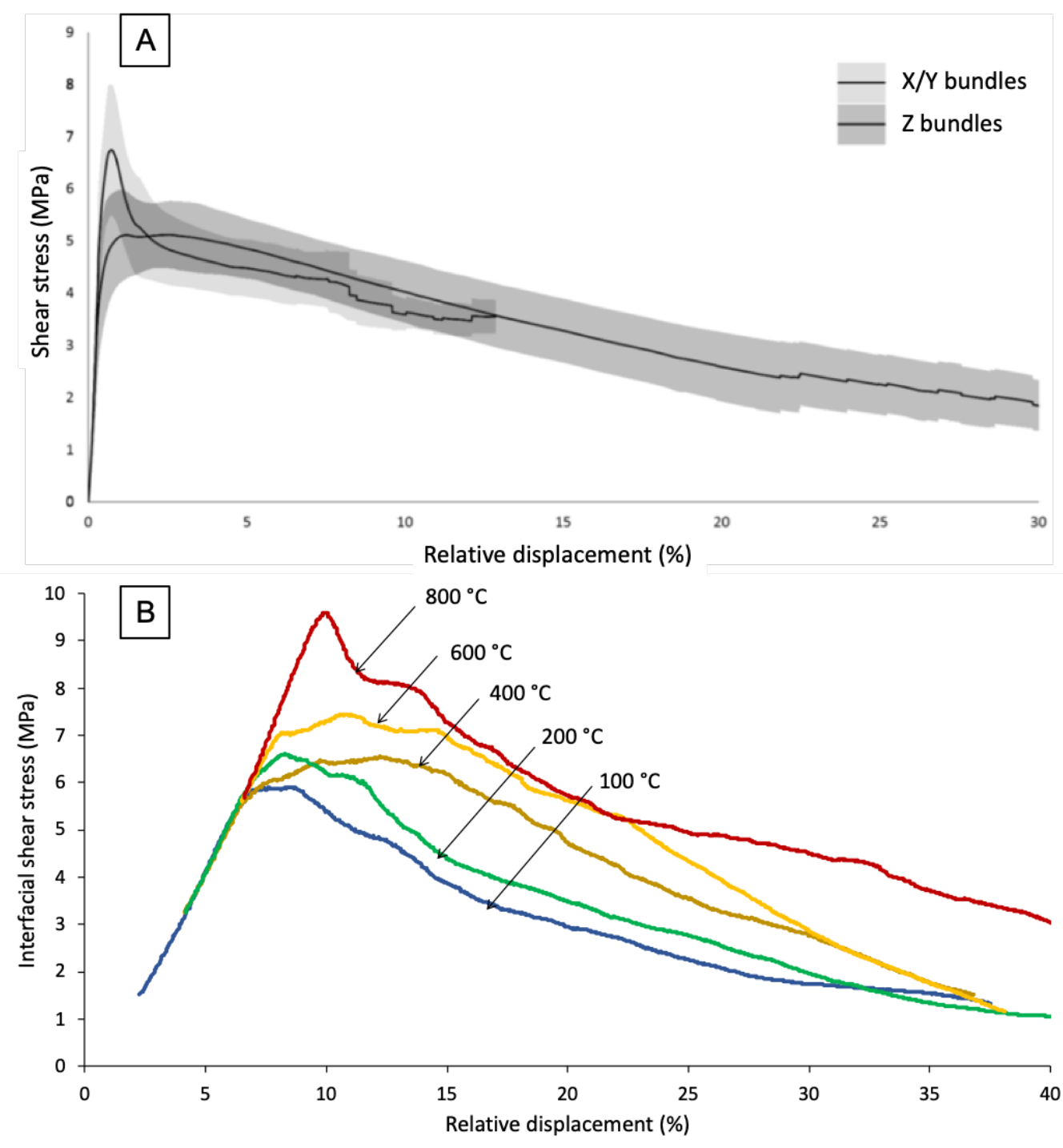

Figure 4: A. Summary of push-out curves obtained on $\mathrm{X} / \mathrm{Y}$ and $\mathrm{Z}$ yarns at ambient temperature. The shaded zones indicate confidence intervals. B. Typical experimental push-out curves obtained at various temperatures on $\mathrm{Z}$ bundles. 


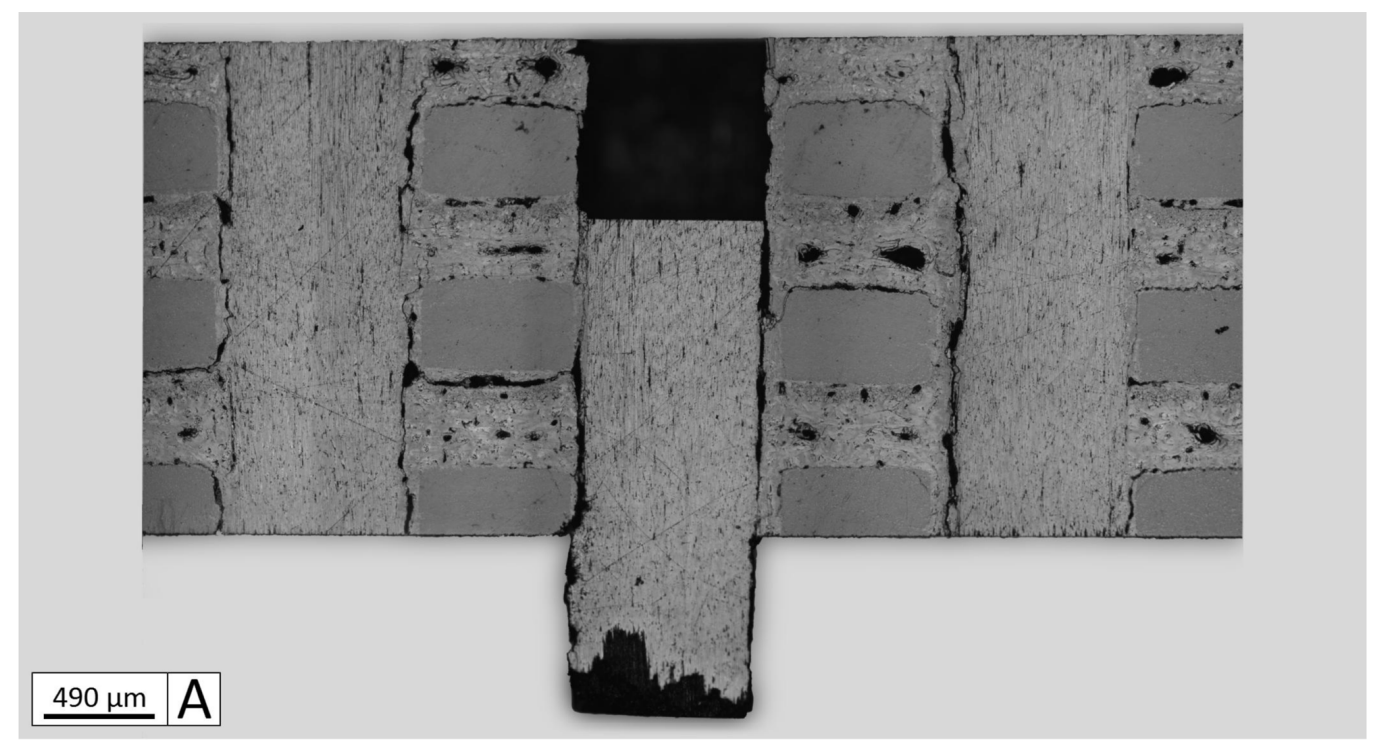

Figure 5: Photograph of a specimen after a yarn push-out test.
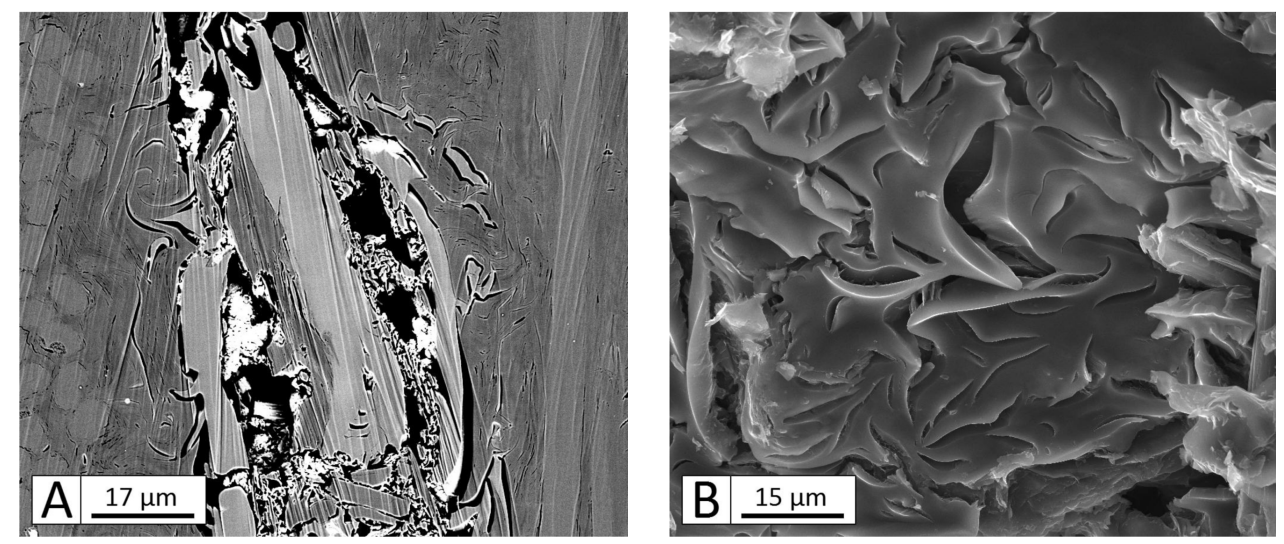

Figure 6: SEM backscattered electron micrographs of lateral (A) and front (B) views of the mesoscale interface between bundles.

\subsubsection{Description of the chosen model}

There exists a wealth of interface models that can be considered for the current model. Recent cohesive zone models (CZM) feature friction on a damaged part 
of the interface, with a fracture energy on the undamaged part of the surface [3234] ; a variation accounting for dilatance has also been developed [35]. However, these models necessitate an initial cohesive behavior, which is not the case for our interfaces, and then do not easily incorporate initial opening. For these reasons, we rather considered an ad hoc interface model that better suits our needs.

The morphology of the mesoscale interfaces features a large initial decohesion around the mesoscale constituents; a marked roughness and the intercalation of debris (see fig. 6)A ) are nevertheless able to maintain the assembly as a whole. When temperature increases, the decohesion gap diminishes until total disappearance and the friction energy in push-out tests increases. Therefore, it is rather natural to set up an interface model that includes three sliding regimes, according to the degree of interface opening: if the lids are far apart from each other, then there is no sliding shear stress; when they get closer, sliding occurs and the shear stress increases, accounting for the roughness of the interface; finally, when they become very close, the shear stress increases very strongly until the locking of the interface. This is summarised in fig. 7C, where two parameters, $\Delta=-d_{c}$ and $\delta=1 / 2\left(d_{0}+d_{c}\right)$, are morphological parameters linked to the average interface aperture and to the average roughness height respectively, as illustrated in fig. 7B . Figs. 7D-E provide the necessary relationships giving the normal and tangential stresses as functions of the normal and tangential displacements, respectively. The mode I behavior, described by figure 7D, gives the normal stress as a function of the normal displacement : it is null if there is no contact, while it gives a stiff elastic trial response when contact is obtained, i.e. when $u_{n}<d_{c}$ :

$$
\sigma_{n}=\left\{\begin{array}{lr}
0 & \text { if } u_{n} \geq d_{c} \\
K\left(u_{n}-d_{c}\right) & \text { else. }
\end{array}\right.
$$

For the mode II/III behavior, the response is less simple. Let $u_{t}^{0}$ be the initial 
value of the displacement; then, one defines an elastic response as :

$$
\sigma_{t, i}^{e l}=\left\{\begin{array}{lr}
0 & \text { if } u_{n} \geq d_{c} \\
K\left(u_{t, i}-u_{t, i}^{0}\right) & \text { else. }
\end{array} \quad i=1,2\right.
$$

A Coulomb-like stress criterion is built using $\sigma_{t}^{e l}$, a combination of both components of the tangential stresses:

$$
\sigma_{t}^{e l}=\sqrt{\left(\sigma_{t, 1}^{e l}\right)^{2}+\left(\sigma_{t, 2}^{e l}\right)^{2}}
$$

If this quantity is superior to the sliding shear stress $\tau_{s}$, then sliding occurs, until the tangential stress becomes inferior again to the sliding stress. This is achieved in the following manner. If $\tau_{s}+\sigma_{t}^{e l} \geq 0$, then $u_{t, i}^{0}$ is incremented :

$$
u_{t, i}^{1}=u_{t, i}^{0}+\left(1+\frac{\tau_{s}}{\sigma_{t}^{e l}}\right) \frac{\sigma_{t, i}^{e l}}{K}, i=1,2
$$

and the tangential stress is computed as :

$$
\sigma_{t, i}=\left\{\begin{array}{lr}
0 & \text { if } u_{n} \geq d_{c} \\
K\left(u_{t, i}-u_{t, i}^{1}\right) & \text { else. }
\end{array} \quad i=1,2\right.
$$

where $\mu K_{r}$ is the parameter that relates the increase of the sliding stress $\tau_{s}$ to the closing of the interface.

Sliding will continue until the condition is not met any more. As illustrated in Fig. 7C, the sliding stress is given as a piecewise continuous function of the normal displacement $u_{n}$ :

$$
\tau_{s}=\left\{\begin{array}{lr}
0 & \text { if } u_{n} \geq d_{0} \\
\mu K_{r}\left(u_{n}-d_{0}\right) & \text { if } d_{0} \geq u_{n} \geq d_{c} \\
\mu K_{r}\left(d_{c}-d_{0}\right)+\mu K\left(u_{n}-d_{c}\right) & \text { else. }
\end{array}\right.
$$



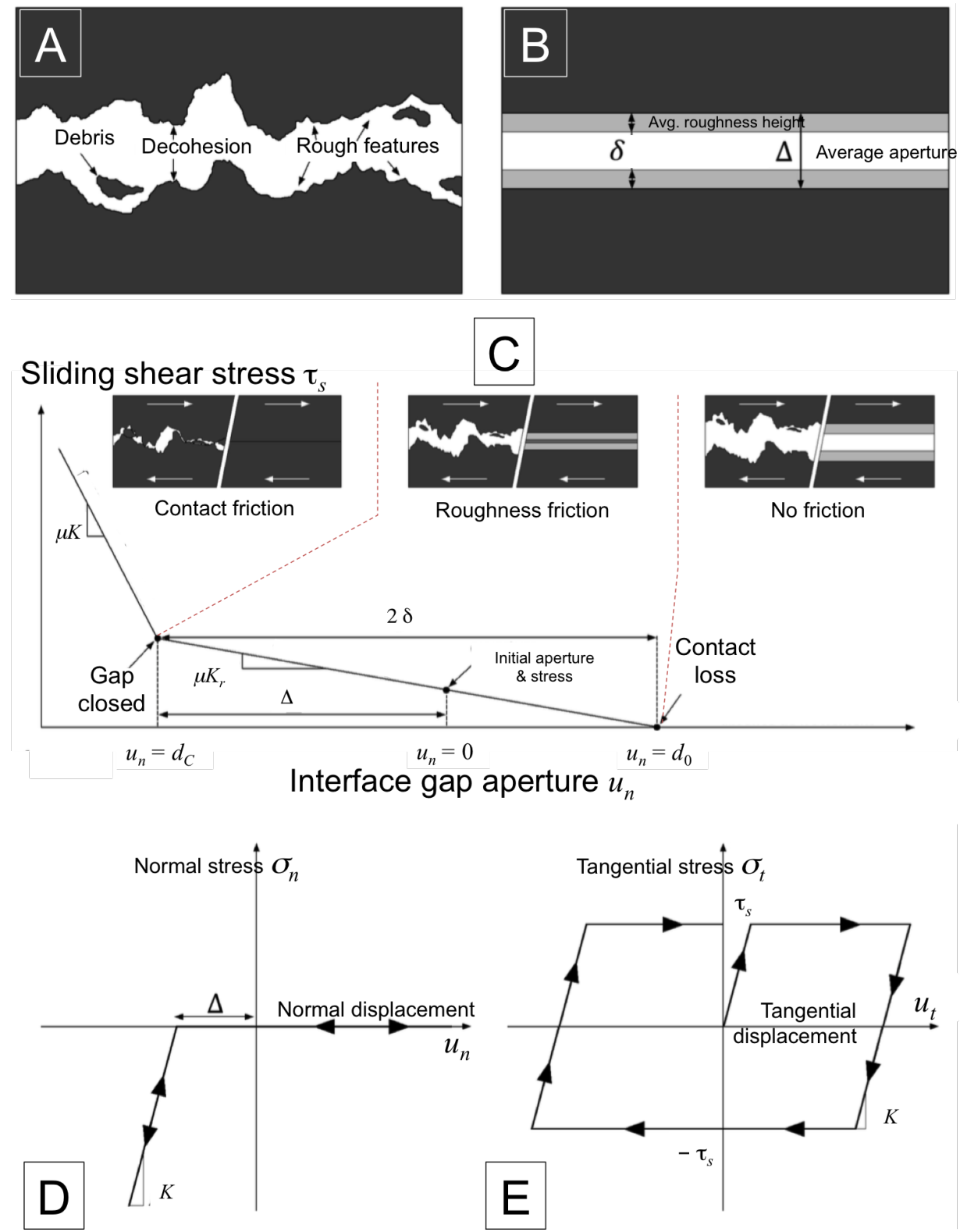

Figure 7: Model for the interface behavior. A: scheme of an actual interface; B: characteristic lengths of the interface used for the model; C: Sliding shear stress vs. normal displacement (opening) (see eq. 6); D : Mode I behavior : normal stress vs. normal displacement (see eq. 1) ; E : Modes II/III behavior : tangential stress vs. tangential displacement (see eqs. 2-5). 
This model is therefore able to represent opening/closing of interfaces in mode I, with a sufficiently strong prevention of interpenetration (provided the stiffness $\mu K$ is sufficient), and in the same time to account for boundary sliding with friction, which will suffice for the representation of the material behavior in the present study.

\subsubsection{Identification procedure}

In the model, the stiffness constant $\mu K$ is chosen deliberately with a very high value (here, $10^{8} \mathrm{MPa}^{-\mathrm{mm}^{-1}}$ ), because it has mainly a numerical role and not a purely physical one. Indeed, the low- $u_{n}$ part of the curve plotted in fig. 7C should be vertical to represent a perfect contact, but this is numerically impossible to handle. Moreover, a sliding coefficient $\mu$ of 0.3 has been chosen arbitrarily, knowing that tuning the other coefficients of the model will suffice to allow reproducing the experimental behavior. The only physically meaningful parameters in this model are $\mu K_{r}$ and the aperture parameters $\Delta$ and $\delta$. These last two parameters (see fig. 7B) can be readily obtained from micrographs and tomographs of the material. Retained values are listed in Table 2. Yet, the value of $\mu K_{r}$ needs to be calibrated using an inverse identification procedure that is now described. Push-out tests simulations have been performed on resolution domains having approximately the same size as the real samples, centered on the yarn receiving the load, as described in Figure 8 . The load has been simulated by selecting a circular region on the top of the yarn and applying a common fixed load to all the nodes within this area. The rear-face reaction is obtained by setting fixed null displacements to all nodes except a circular region $2 \mathrm{~mm}$ in diameter centered on the pushed yarn axis. The displacement and load of the central node on top of the pushed yarn provide the observables : stress by dividing the applied load by the contact area around the yarn and relative displacement by dividing by the sample thickness. Various thicknesses (1.6, 2.0 and $2.4 \mathrm{~mm})$ and orientations $(\mathrm{X} / \mathrm{Y}$ or Z) were 
tested, at different temperatures from ambient to $1000^{\circ} \mathrm{C}$. After optimization of the parameters, the simulation results reproduce correctly the experimental data, as illustrated in Figure 8C. The curves feature a first loading stage during which the whole sample undergoes progressive biaxial flexure, then sliding begins : the load does not increase any more while the displacement increases. For X/Y pushout tests, the behavior is more intricate. First, the experimental push-out tests have shown that there is a maximal stress reached, with an immediate posterior decrease: it is an unlocking phenomenon, linked to the slightly undulated geometry of the real samples [30]. Since the undulation has not been reproduced in the simulations, the unlocking phenomenon is not reproduced either. Moreover, the transverse yarns undergo twisting; they end up pinching the pushed yarn, resulting in a final increase of the simulated average stress, whereas in the experiments there is probably some increase of the degradation state of the interface, which prevents this stress increase. This limitation of the model, though very visible on push-out experiments, has a minute impact on the forthcoming non-linear stressstrain tests, because in the latter case the sliding displacements are very small. Also for this reason, it was more interesting to have a correct fit of the model in the small-displacement part of the push-out curves rather than on the fully established plateau.

The effect of temperature, which narrows the interfaces and therefore increases the maximal shear stress during push-out, is correctly reproduced in the model, without any other parameter adjustment, as illustrated in Fig. 9. This validates a posteriori the model hypothesis that the increase of friction is only due to the differential thermal expansion of the bundles. 

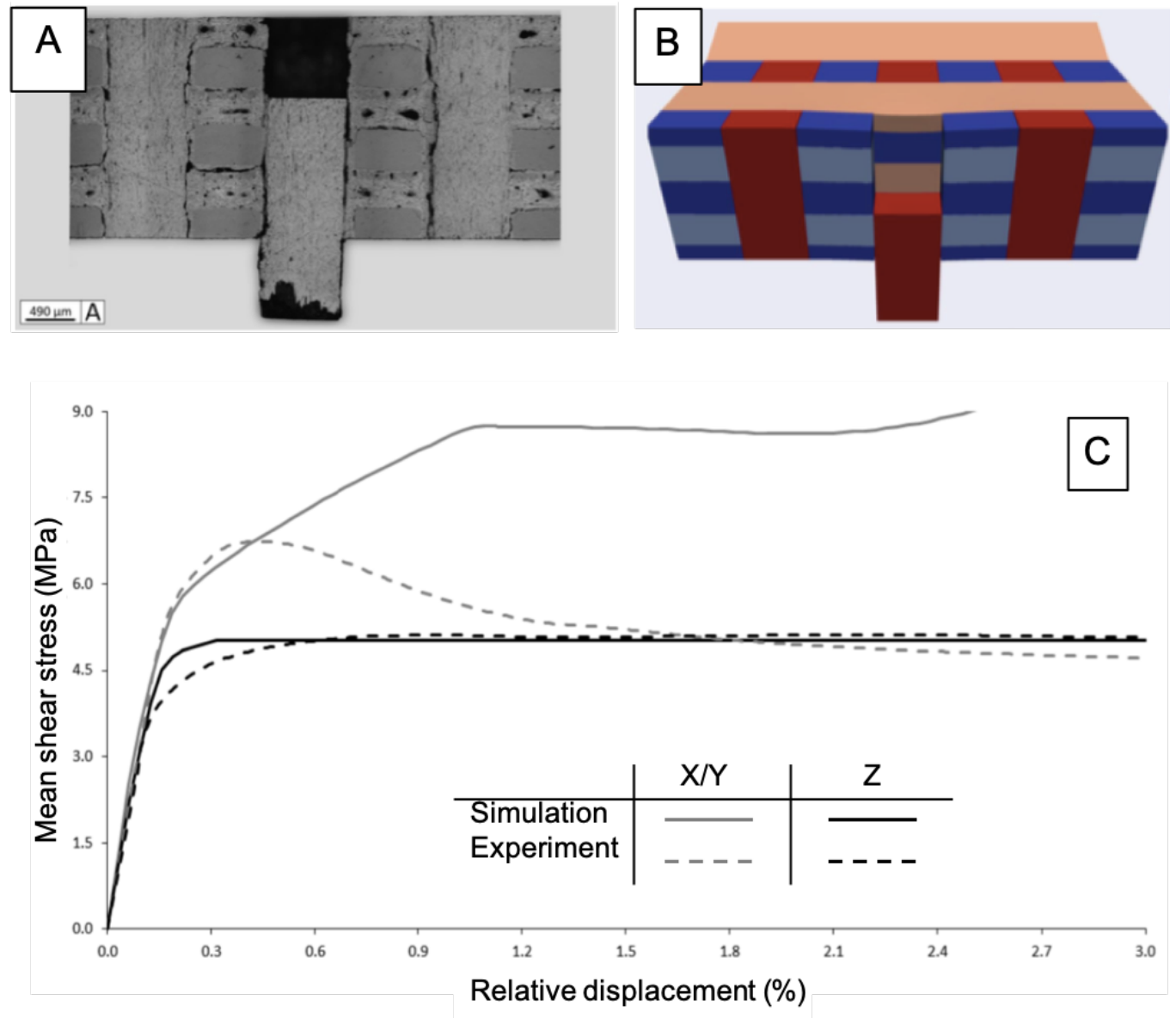

Figure 8: Full yarn push-out simulations. A: Experimental cross-section observation of the sample after test ( $\mathrm{Z}$ direction). B: Rendering of the simulated test (elastic part of deformation has been multiplied by 20). C: Push-out curves : simulation and experiment, in $\mathrm{X} / \mathrm{Y}$ and $\mathrm{Z}$ directions. 


\begin{tabular}{l|c|c|c|c|c}
\hline $\begin{array}{l}\text { Normal } \\
\text { orientation }\end{array}$ & $\Delta$ & $\delta$ & $\mu K_{r}$ & \multicolumn{2}{|c}{$\tau_{s}(\mathrm{MPa})$ at : } \\
& $(\mu \mathrm{m})$ & $(\mu \mathrm{m})$ & $\left({\left.\mathrm{MPa} . \mathrm{mm}^{-1}\right)}^{-}\right.$ & $u_{n}=0$ & $u_{n}=-\Delta$ \\
\hline \hline $\mathrm{Z}$ & 20.0 & 12.5 & 3210 & 5.00 & 25.0 \\
$\mathrm{X} / \mathrm{Y}$ & 10.0 & 6.25 & 990 & 8.00 & 40.0 \\
\hline
\end{tabular}

Table 2: Interface properties of the model. $D$ has been measured from micrographs; $\tau_{s}\left(u_{n}=0\right)$ is obtained from experimental curves, $d$ and $\mu K_{r}$ are identified in order to reproduce the correct $\tau_{s}\left(u_{n}=0\right)$, and $\tau_{s}\left(u_{n}=-\Delta\right)$ is computed from the model.

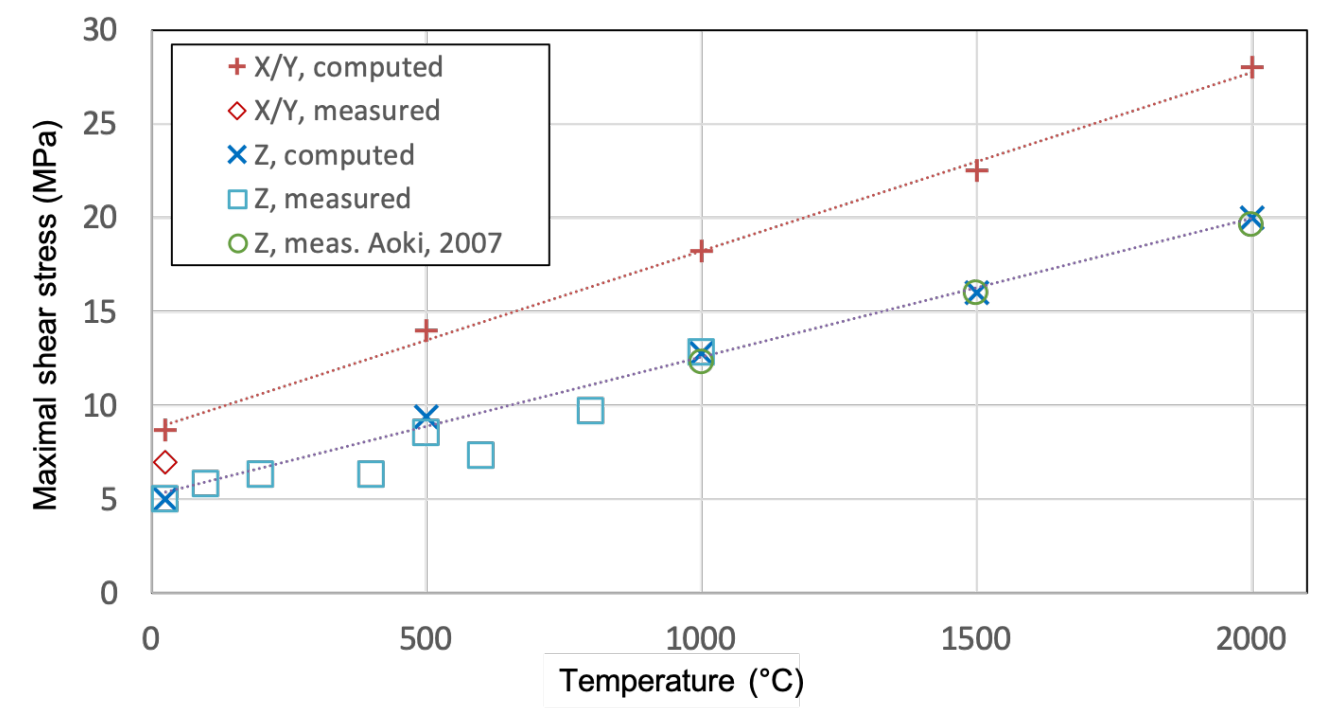

Figure 9: Evolution of maximal stress of Z- and X/Y-bundles with temperature - comparison between experimental values and computations. Experimental data above $1000^{\circ} \mathrm{C}$ are taken from [17].

\subsection{Mesoscale model optimization and validation}

The mesoscale model was validated against two types of tests : first, a determination of the effective mechanical properties along the main axes ; second, a simulation of the the heat expansion behavior. 


\subsubsection{Optimization of the bulk elastic properties}

The macroscopic elastic tensor of the material has been computed using the model described above, in a resolution domain containing an integer number of RUCs, with Periodic Mixed Uniform Boundary Conditions (PMUBC) [36]. Six tests were performed : three tractions along the $\mathrm{X}, \mathrm{Y}$ and $\mathrm{Z}$ directions, and three pure shear tests along $\mathrm{XY}, \mathrm{YZ}$ and $\mathrm{XZ}$. In each case, the average stresses were recorded and, thanks to the knowledge of the imposed strain tensor, the full elastic tensor was obtained; from it, Young moduli, shear moduli and Poisson ratios were computed. Some uncertain parameters relative to the elastic behavior of the constituents (namely, the transverse and shear properties of the yarns and the elastic modulus of the matrix) have been altered to obtain a more accurate fit. Actually, the Poisson moduli have almost no significance in the further computations since the presence of the interfaces cancels the Poisson effect of the constituents. Likewise, it has been noted that the elastic properties of the interfaces were not critical at all in these computations. Table 3 describes the quality of the best fit with respect to published results. Table 4 summarizes the values of the constituent coefficients, after optimization, given in comparison with the experimental data. There is a very significant difference in the matrix modulus between the literature value and optimised model value. It has to be noted that the matrix values from past works have also been obtained indirectly from experiments on bundles and on composites, using a mechanical behavior model, as in the present work. So, the differences in the values arise principally from the distinct nature of the models used for the identification.

It is also seen that the yarn tensile properties fully dominate the composite effective moduli, in its principal directions. This could be expected because of the extremely anisotropic properties of the bundles. However, in the case of shear, yarns and pockets have comparable contributions. 


\begin{tabular}{l|ccccc}
\hline & Young modulus & \multicolumn{2}{c}{ Poisson coefficients } & \multicolumn{2}{c}{ Shear moduli } \\
& $E_{i}$ & $v_{X Y}$ & $v_{k Z}$ & $G_{X Y}$ & $G_{k Z}$ \\
\hline \hline Computed & $120 \mathrm{GPa}$ & 0.01 & 0.005 & $2.75 \mathrm{GPa}$ & $2.25 \mathrm{GPa}$ \\
Experimental & $120 \mathrm{GPa}$ & $\approx 0.02$ & $\approx 0.02$ & $2.75 \mathrm{GPa}$ & $2.25 \mathrm{GPa}$ \\
\hline
\end{tabular}

Table 3: Computed elastic properties compared to experimental values $[8,9] .(i, j) \in\{X ; Y ; Z\}^{2}$, $k \in\{X ; Y\}$.

\begin{tabular}{|c|c|c|c|c|c|c|c|}
\hline & & \multicolumn{2}{|c|}{$\begin{array}{c}\text { Young's modulus } \\
(\mathrm{GPa})\end{array}$} & \multicolumn{2}{|c|}{$\begin{array}{c}\text { Poisson coefficient } \\
(-)\end{array}$} & \multicolumn{2}{|c|}{$\begin{array}{c}\text { Shear modulus } \\
\text { (GPa) }\end{array}$} \\
\hline & & $E_{L}$ & $E_{T}$ & $v_{L T}$ & $v_{T T}$ & $G_{L T}$ & $G_{T T}$ \\
\hline \multirow{2}{*}{ Literature } & Yarn & $484 *$ & $6.0^{*}$ & 0.25 & 0.45 & $1.7 *$ & 2.1 \\
\hline & Matrix & \multicolumn{2}{|c|}{3.6} & \multicolumn{2}{|c|}{0.15} & \multicolumn{2}{|c|}{2.0} \\
\hline \multirow{2}{*}{ This work } & Yarn & 473 & 6.0 & 0.25 & 0.45 & 1.7 & 1.1 \\
\hline & Matrix & \multicolumn{2}{|c|}{19.3} & \multicolumn{2}{|c|}{0.15} & \multicolumn{2}{|c|}{8.39} \\
\hline
\end{tabular}

Table 4: Bulk mechanical properties of the material mesoscale constituents, in model after optimization, and compared to literature values $[8,9]$. Only values marked with an asterisk have been obtained directly from experiments. $L$ means "Longitudinal", $T$ is "Transverse". The parameter values that have not been considered for optimization are in italic.

Computations have been carried out on the same resolution domain, but turning alternatively to zero the elastic properties of each type of constituent, including the interfaces. The relative variations of the moduli upon each suppression can be considered as sensitivity indicators. They are summarized in Table 5. We can readily see that the longitudinal properties of the yarns are fully critical for the onaxis moduli of the composite, as could be expected from their highly anisotropic properties and spatial arrangement, whereas its shear behavior depends not only on the yarn shear moduli but also on the matrix pockets modulus. Finally it is seen that replacing the frictional interface by perfect interfaces does not affect deeply 
the effective properties investigated here. This is also why the interface properties have not been optimized here.

\begin{tabular}{l|l|c|c|c|c}
\hline \multirow{2}{*}{ Constituent } & \multirow{2}{*}{ Property } & \multicolumn{4}{|c}{ Effective composite properties } \\
\hline \hline \multirow{3}{*}{ Yarns } & $E_{L}$ & $100 \%$ & $100 \%$ & $2 \%$ & $2 \%$ \\
& $E_{T}$ & $<1 \%$ & $4 \%$ & $2 \%$ & $<1 \%$ \\
& $G_{L T}$ & $<1 \%$ & $4 \%$ & $31 \%$ & $40 \%$ \\
& $G_{T T}$ & $<1 \%$ & $4 \%$ & $16 \%$ & $24 \%$ \\
\hline \multirow{2}{*}{ Matrix pockets } & $E$ & $<1 \%$ & $4 \%$ & $35 \%$ & $31 \%$ \\
\hline \multicolumn{2}{l|}{ Interfaces (perfect vs. sliding) } & $8 \%$ & $8 \%$ & $3 \%$ & $8 \%$ \\
\hline
\end{tabular}

Table 5: Dimensionless sensitivity of the model output values to its parameters.

\subsubsection{Thermal expansion simulations}

The second series of model validations is the simulation of heat expansion experiments. Homogenization computations have been carried out on the same cubic representative elementary volume as before, still using the PMUBC; in that case, the cell dimensions are fixed and the thermal expansion factor is retrieved from the internal stresses and the compliance tensor. Computations have been made with and without sliding interfaces for sake of comparison. Fig. 10 is a plot of the two simulated TMA curves, compared to the experimental data. It is readily seen that the computation with sliding interfaces correctly predicts the non-linear thermal behavior (contraction at low $\mathrm{T}$, then expansion), but underpredicts the linear expansion rate at high temperatures. The heat expansion curve simulated with perfect interfaces shows a very large over-prediction of heat expansion at high temperatures. A more accurate model could be constructed not only including sliding interfaces, but also taking into account the slight waviness of the bundle shapes, which implies a partial locking of the interfaces at high temperatures. It 
is seen in this example that, as opposed to the case of elastic tests, the effect of interfaces is determining. Therefore we validate here the fact that including interfaces is crucial for a simulation of this material, even though the fidelity of the simulation could be improved.

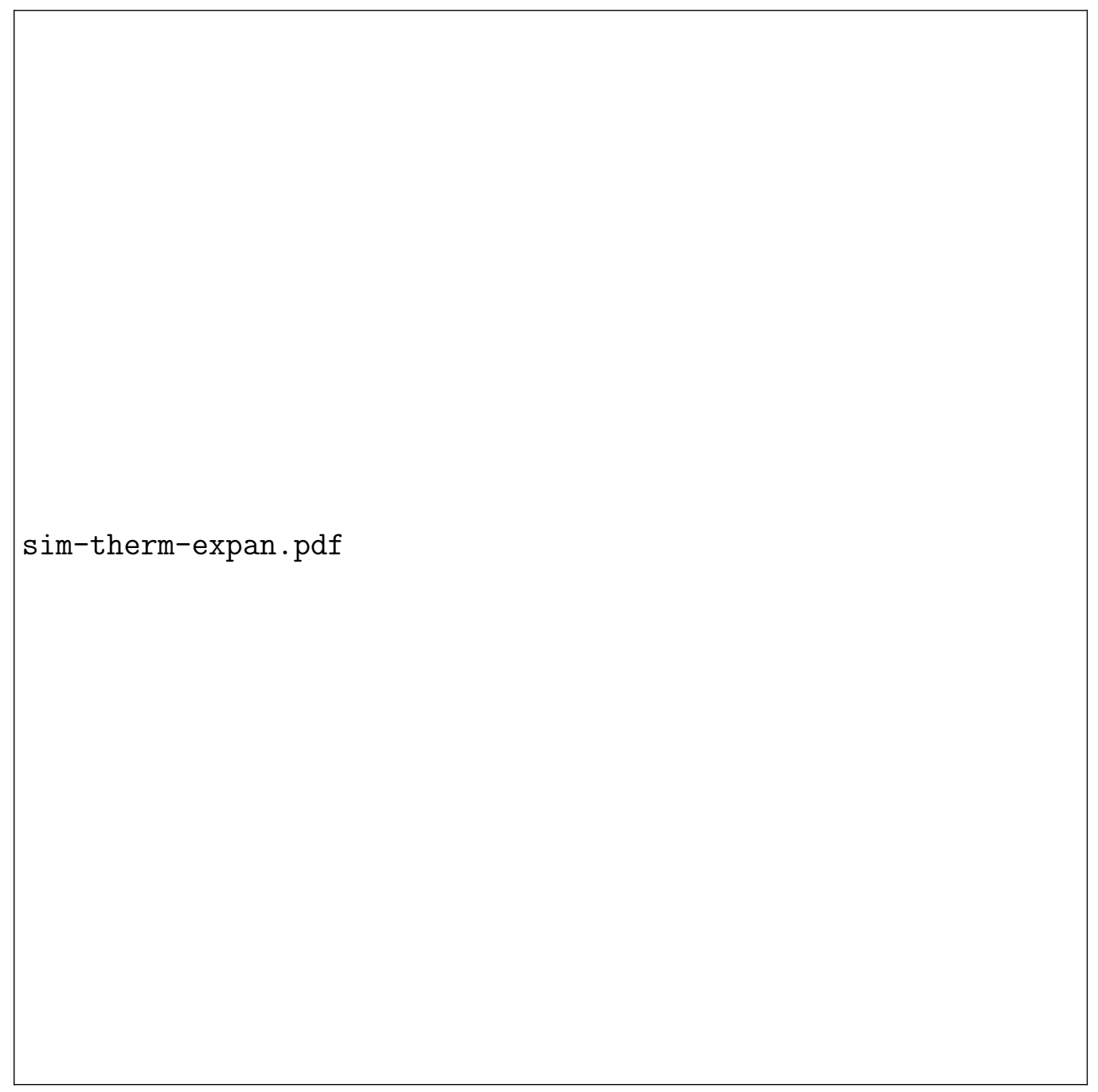

Figure 10: Thermomechanical analysis (TMA) curves, simulated by homogenization (see text) with and without sliding interfaces, compared to experimental results. 


\section{Non-linear mechanical behavior: results and discussion}

\subsection{Off-axis $\left(45^{\circ}\right)$ tensile/compressive testing}

As opposed to on-axis tests, much more data describing the material nonlinear behavior is available in off-axis tests. Such tests are therefore of particular interest to validate the model. The simulated tests are performed on $3.2 \times 3.2$ $\times 6.4 \mathrm{~mm}^{3}$ resolution domains, containing the same type of elements as in the preceding computations. All model parameters have been taken from Table 4 . The boundary conditions were handled in the same way as before.
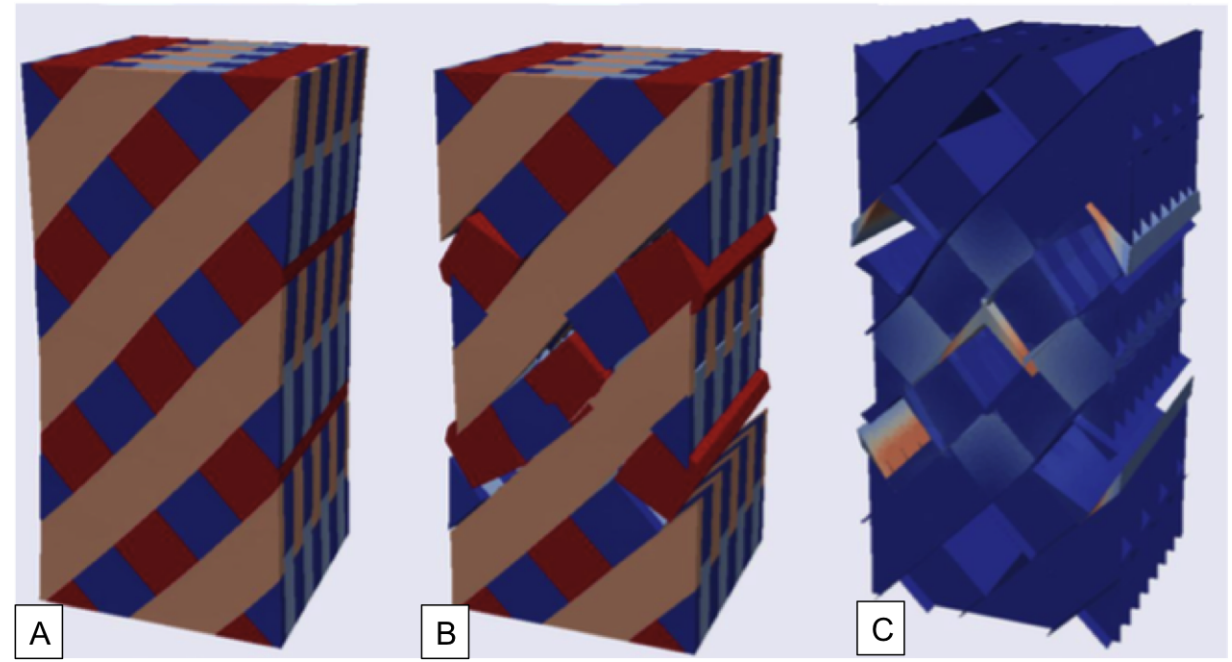

Figure 11: $45^{\circ}$ off-axis tests simulations rendering by exaggerated strain of : A. the volumic mesh with perfect interfaces; B: the same, with sliding interfaces; C: interfaces only (blue:no sliding, red: sliding).

A comparison of figs. $11 \mathrm{~A}$ and $\mathrm{B}$ illustrates well the way the non-perfect interfaces work during a tensile test, mostly by shear - as observed by Hatta et al. [12], and that their opening allows the transverse bundles to rotate around their main axis. Fig. $11 \mathrm{C}$ shows that there is a very strong effect of the boundaries: this phenomenon had been observed previously on a similar material [37] and on a 4-directional composite [38-40]. 

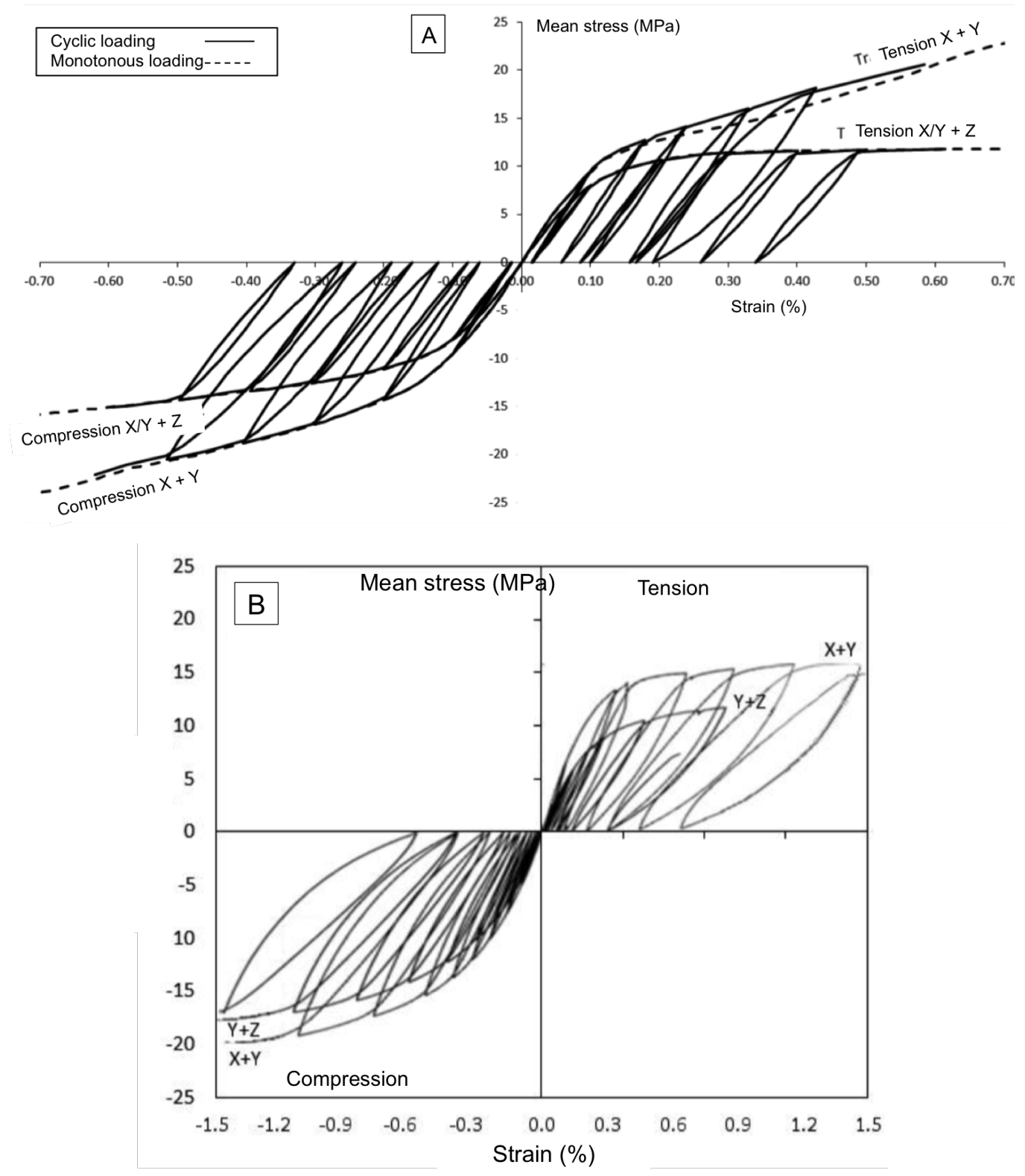

Figure 12: $45^{\circ}$ off-axis tests simulations. A : simulated cyclic and monotonous tests in the $\mathrm{X}+\mathrm{Z}$ and the $\mathrm{X}+\mathrm{Y}$ directions. $\mathrm{B}$ : Experimental data on two samples of a tri-orthogonal 3D carbon/carbon composite with different sizes [11] 
Figures 12 and 13 describe the strongly non-linear behavior of the composite material model during monotonous or cyclic tensile/compressive off-axis tests, denoted by the marked slope breaks and by the large hysteresis loops. The transition from a quasi-elastic to a pseudo-plastic behavior is rapid; in the plateau regions, the residual strain may be very large $(>0.1 \%)$. Experimental results obtained on a similar material [11] (fig. 12B) are qualitatively well reproduced. As observed experimentally [8], the $\mathrm{X}+\mathrm{Y}$ direction undergoes less damage than the $\mathrm{X} / \mathrm{Y}+\mathrm{Z}$ directions: when disposed transversally, the $\mathrm{Z}$ bundles give a better "interlocking" character to the material than the $\mathrm{X}$ or $\mathrm{Y}$ bundles. 

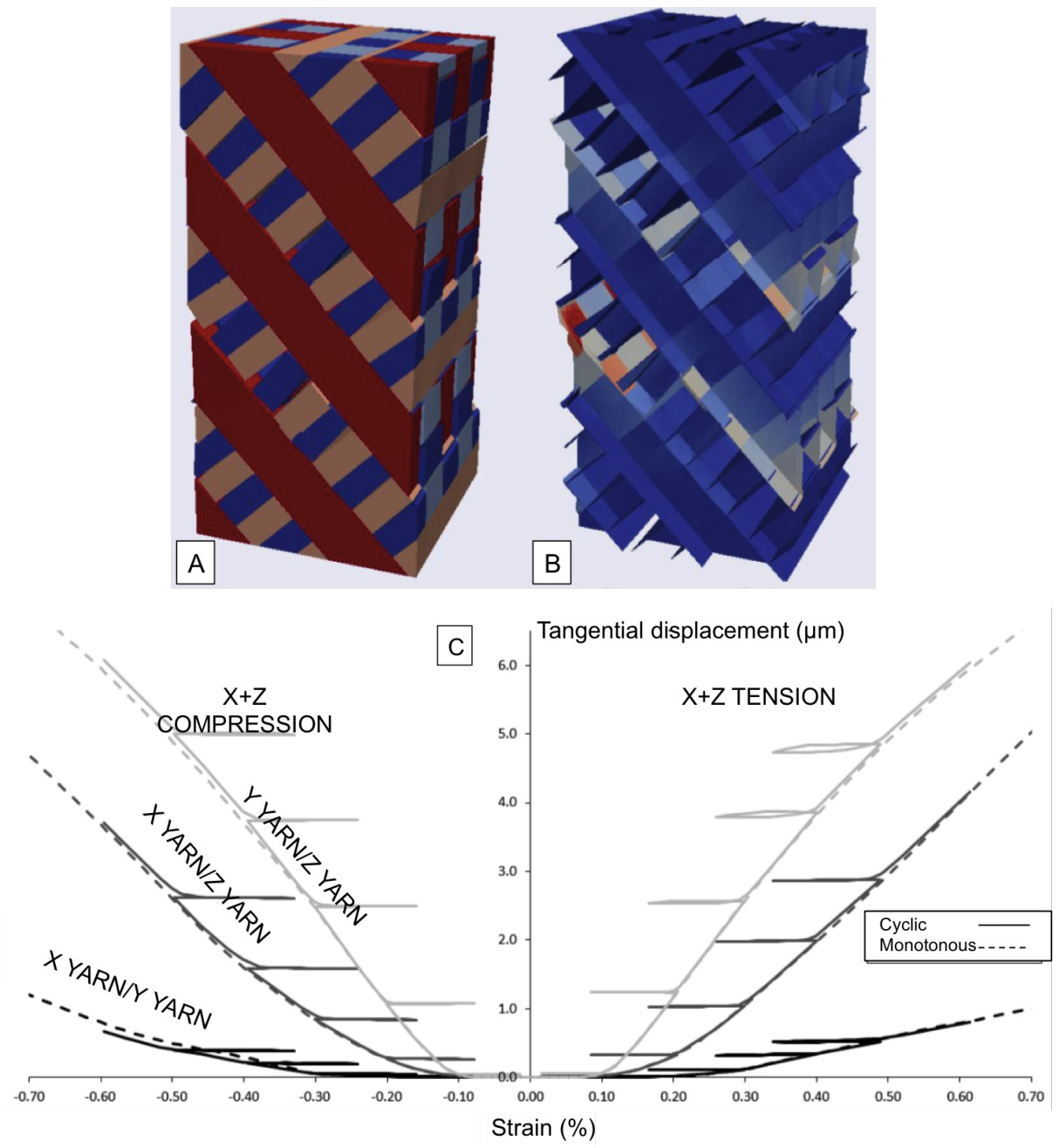

Figure 13: $45^{\circ}$ off-axis test simulation in $\mathrm{X}+\mathrm{Z}$ direction. A: rendering of the volumic mesh with exaggerated displacements; B: rendering of the interfaces only (red: sliding, blue: not sliding); C: Sliding tangential displacement $v s$. strain for tensile and compressive tests. 
Figure 13 plots the tangential sliding at all interfaces as a function of tensile or compressive strain for the $\mathrm{X} / \mathrm{Y}+\mathrm{Z}$ direction. The irreversible behavior is clearly visible : upon cycling, the sliding displacement almost does not diminish; its cumulative value is slightly higher than in monotonous tests. Moreover, it is higher for interfaces around the $\mathrm{Z}$ bundles, because they are more rigid than the $\mathrm{X} / \mathrm{Y}$ bundles, which have half of their section. Together with interface sliding, some rotation of the transverse bundles can also be noticed. 

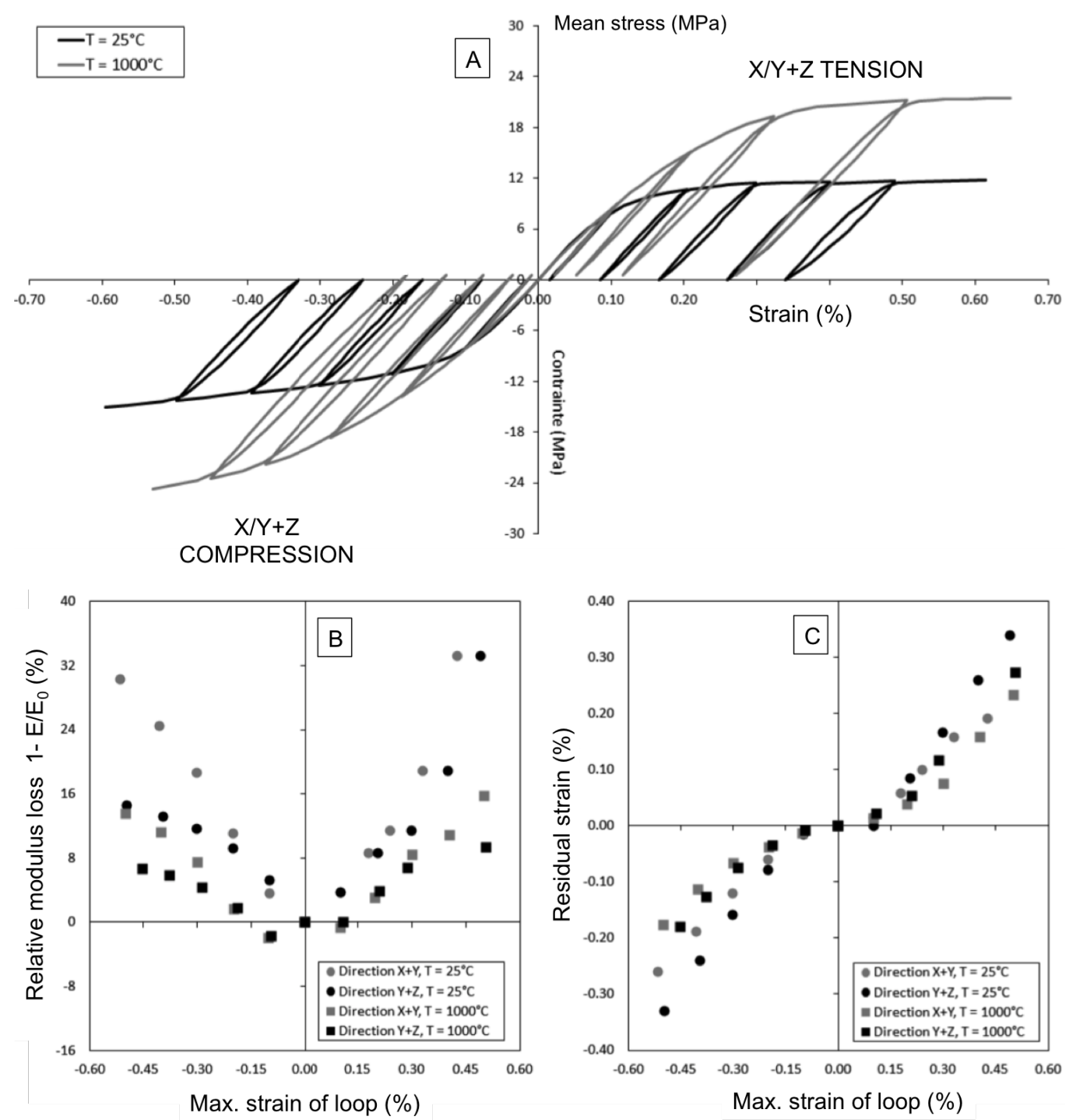

Figure 14: $45^{\circ}$ off-axis test simulation in $\mathrm{X}+\mathrm{Z}$ direction at 25 and $1000^{\circ} \mathrm{C}$. 
The effect of temperature is illustrated in figure 14. On the stress-strain curve (fig. 14A), a very marked increase of the plateau height is visible, as already observed experimentally [12]. The modulus decrease is neatly lower at high temperature (fig. 14B) but still remains positive; the amplitude of the residual strain is also lower at high temperature (fig. 14C). All these elements arise from the fact that the interfaces are much less open at $1000^{\circ} \mathrm{C}$, because of heat expansion, as was already the case in on-axis tensile/compressive tests.

\subsection{Torsional testing}

The simulated tests are performed on cylindrical resolution domains with 4.8 $\mathrm{mm}$ height and $4.8 \mathrm{~mm}$ diameter, containing the same type of elements as in the preceding computations. All model parameters have been taken from Table 4 . The boundary conditions were handled in the same way as before. We will describe here the results of the $\mathrm{Z}$ torsional test, achieved either monotonically or with unloading-reloading cycles. 

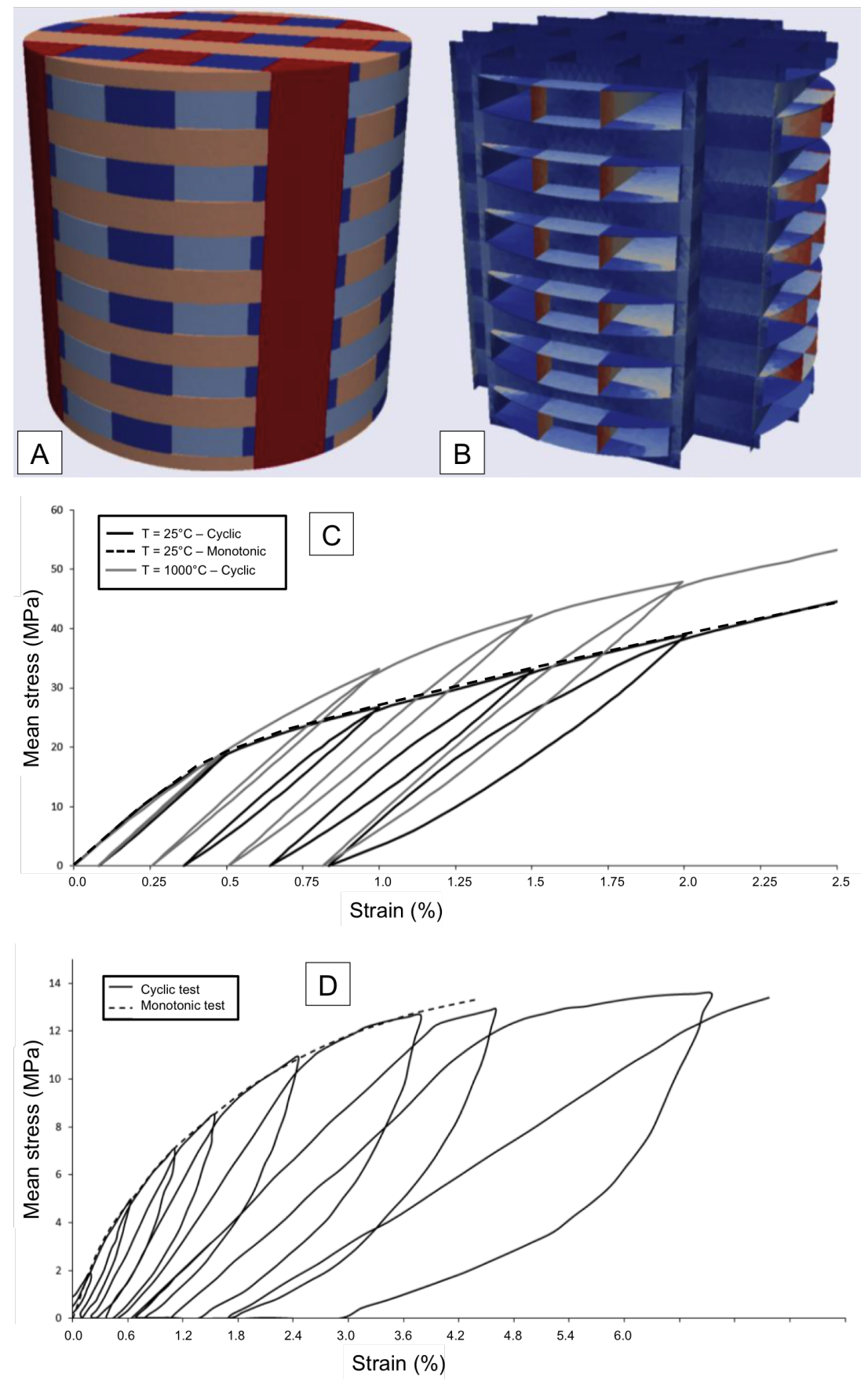

Figure 15: $\mathrm{Z}$ torsion tests. A : rendering of the volumic mesh with exaggerated displacements; B : rendering of the interfaces only (red: sliding, blue: not sliding); C: simulated test at 25 and $1000^{\circ} \mathrm{C}$ on a sample with $4.8 \mathrm{~mm}$ height and diameter; D: experimental results obtained at ambient temperature on a sample with $16 \mathrm{~mm}$ height and $19.2 \mathrm{~mm}$ diameter [9]. 
The sample behavior is depicted schematically in figs. 15A and B. The most important sliding occurs around the matrix pockets; then, the interfaces between $\mathrm{X}$ and $\mathrm{Y}$ bundles have an appreciable sliding movement; finally, there is also some sliding around the $\mathrm{Z}$ bundles, probably due to their bending solicitation. The stress-strain curves (fig. 15C) show a rapid transition to non-linear behavior, with large loops upon cycling. Again, at high temperature, the material resistance is higher and the interface sliding is lower, for the same reason as before, i.e. a closing of the interfaces due to the heat expansion of the constituents. As compared to experimental results obtained on the same material with other dimensions (fig. 15D) [9], it is seen that the model qualitatively reproduces the material behavior, though it is much stiffer and has much less damage. Size effects could be invoked to explain the discrepancies, but intra-bundle damage is more likely to occur. This progressive damage is evidenced on the experimental test curve by the decrease of the modulus at the beginning of each reloading cycle but it is not taken into account in the model.

\section{Conclusion and outlook}

This documentpaper has presented the construction and the validation of a mechanical model for a 3D carbon/carbon composite at temperatures ranging from ambient to relatively high values $\left(1000^{\circ} \mathrm{C}\right)$. Its principal ingredients are, in addition to the individual constituents ( $\mathrm{X} / \mathrm{Y}$ and $\mathrm{Z}$ bundles, matrix pockets), the interfaces between them, which are capable of opening and sliding. The latter have been modeled by the insertion of interface elements in the FE model of the 3D material architecture. The interfacial properties have been identified from push-out tests and morphological observation. As opposed to previously existing models, the current one is based on the material microstructure. It has allowed to reproduce successfully experimental off-axis $\left(45^{\circ}\right)$ tensile/compressive tests and quali- 
tatively replicates torsion tests, without any parameter fitting. In the off-axis tests, interfaces opening and sliding, as well as local rotations of the transverse bundles are shown to be responsible for the non-linear behavior of the material samples. In the torsion tests, the most important sliding occurs around the matrix pockets. The role of temperature, which stiffens the material due to heat expansion and interface closure, is successfully reproduced.

More work can be done in order to improve the fidelity of this model. First, the sliding interface models can be enriched by the addition of a blocking phenomenon. This would allow the reproduction of the preferential damage direction in the case of macroscopic heat expansion tests. Second, the effect of temperature on the bulk elastic properties is only accounted for by an abatement of the elastic modulus and indirectly by the effects of heat expansion; however, it is known that above $\approx 1600^{\circ} \mathrm{C}$, the material constituents begin to creep. Therefore, the incorporation of a visco-elasto-plastic law would be beneficial to model the material behavior at very high temperatures. Finally, the model includes only pre-existing sliding interfaces between the constituents, whereas it is possible that the actual material develops more damage through the opening and progression of cracks inside the bundles themselves, for instance. This seems particularly necessary for the simulation of torsion tests. Adding crack growth to the model is currently under investigation [41].

\section{Acknowledgements}

CEA is gratefully acknowledged for financial support to A. G. under the form of a 3-year PhD grant. TMA measurements have been performed by Julien Genée during his Masters internship with the help of Georges Chollon and Laurine Lapuyade. 


\section{Nomenclature}

\begin{tabular}{|c|c|c|}
\hline Symbol & Meaning & Unit \\
\hline \multicolumn{3}{|c|}{ Latin } \\
\hline$d$ & Diameter & $\mathrm{m}$ \\
\hline$E$ & Young's modulus & $\mathrm{GPa}$ \\
\hline$G$ & Shear modulus & $\mathrm{GPa}$ \\
\hline$K$ & Stiffness parameter & MPa.mm ${ }^{-1}$ \\
\hline$u$ & Displacement & $\mathrm{m}$ \\
\hline \multicolumn{3}{|c|}{ Greek } \\
\hline$\delta$ & Average roughness height & $\mu \mathrm{m}$ \\
\hline$\Delta$ & Average crack aperture & $\mu \mathrm{m}$ \\
\hline$\mu$ & Friction coefficient & - \\
\hline$v$ & Poisson coefficient & - \\
\hline$\sigma$ & Tensile/compressive stress & $\mathrm{MPa}$ \\
\hline$\tau$ & Shear stress & $\mathrm{MPa}$ \\
\hline \multicolumn{3}{|c|}{ Subscripts and underscripts } \\
\hline$\bullet_{c}$ & Related to gap closure & \\
\hline$\bullet$ & Elastic equivalent & \\
\hline$\bullet_{L, T}$ & Related to longitudinal or transverse directions & \\
\hline$\bullet_{n}$ & Normal & \\
\hline$\bullet_{r}$ & Related to roughness & \\
\hline$\bullet_{t}$ & Tangent & \\
\hline$\bullet \bullet_{X, Y, Z}$ & Related to directions $X, Y$, or $Z$ & \\
\hline$\bullet_{0}$ & Related to loss of contact & \\
\hline
\end{tabular}




\section{References}

\section{References}

[1] G. Savage, Carbon/Carbon composites, Chapman \& Hall, London, 1993, ISBN 0-412-36150-7

[2] V. I. Trefilov, Ceramic- and Carbon-Matrix Composites, Chapman \& Hall, London, 1995. DOI: 10.1007/978-94-011-1280-2.

[3] L. M. Manocha, E. Fitzer, Carbon reinforcements and $C / C$ composites, Springer, Berlin, 1998, DOI: 10.1007/978-3-642-58745-0.

[4] G. Duffa, Ablative Thermal Protection Systems Modeling, AIAA Education Series, 2013, DOI:10.2514/4.101717.

[5] G. L. Vignoles, J. Lachaud, Y. Aspa, Environmental effects: Ablation of c/c materials - surface dynamics and effective reactivity, in: N. P. Bansal, J. Lamon (Eds.), Ceramic Matrix Composites: Materials, Modeling and Technology, Wiley \& American Ceramic Society, 2014, Ch. 12, pp. 353 - 384. DOI: 10.1002/9781118832998.ch12.

[6] J.-P. Dumont, P. Ladevèze, M. Poss, Y. Rémond, Damage mechanics for 3-D composites, Composites Structures 8 (2) (1987) 119 - 141. DOI: 10.1016/0263-8223(87)90008-0.

[7] J. L. Perry, D. F. Adams, Mechanical tests of a three-dimensionallyreinforced carbon-carbon composite material, Carbon 14 (1) (1976) 61 70. DOI: 10.1016/0008-6223(76)90084-1.

[8] M. Poss, Endommagement et rupture des matériaux composites CarboneCarbone, Ph.D. thesis, Université Paris VI - Pierre \& Marie Curie, Paris (1982). 
[9] Y. Rémond, Sur la reconstitution du comportement mécanique d'un matériau composite 3D à partir de ses constituants, Ph.D. thesis, Université Paris VI Pierre \& Marie Curie, Paris (1984).

[10] P. Ladeveze, L. Proslier, Y. Rémond, Reconstruction of a 3D composite behaviour from a local approach, in: W. C. Harrigan, J. Strife, A. K. Dingra (Eds.), Procs. $5^{\text {th }}$ International Conference on Composite Materials ICCM5, San Diego, CA, USA, The Metallurgical Society, 1985, pp. 1025 - 1027. ISBN: 0-873-39000-8.

[11] M. Gratton, Comportement d'un composite 3D Carbone-Carbone - Mésomodélisation pour la prévision de la réponse sous choc, Ph.D. thesis, ENS Cachan, Cachan (1998).

URL http: //www . theses.fr/1998DENS0004

[12] H. Hatta, K. Goto, T. Aoki, Strengths of C/C composites under tensile, shear, and compressive loading: Role of interfacial shear strength, Composites Science and Technology 65 (15) (2005) 2550 - 2562. DOI:10.1016/j.compscitech.2005.07.012.

[13] M. Venkat Rao, P. Mahajan, R. K. Mittal, Effect of architecture on mechanical properties of carbon/carbon composites, Composite Structures 83 (2) (2008) 131 - 142. DOI: 10.1016/j.compstruct.2007.04.003.

[14] C. Davy, Rupture d'un composite C-C 3D sous sollicitations complexes Expérimentation et modélisation, Ph.D. thesis, ENS Cachan, Cachan (2001).

[15] C. Sauder, J. Lamon, R. Pailler, The tensile behavior of carbon fibers at high temperatures up to $2400^{\circ} \mathrm{C}$, Carbon 42 (4) (2004) 715-725. DOI: 10.1016/j.carbon.2003.11.020. 
[16] J. Jortner, Effects of Weak Interfaces on Thermal Expansion of 3D carbon/carbon composites, Annual report Contract N00014-82-C-0405 AD155-330, Office of Naval Research, Arlington, VA (1985).

URL http://www.dtic.mil/get-tr-doc/pdf/AD/ADA155330

[17] T. Aoki, Y. Yamane, T. Ogasawara, T. Ogawa, S. Sugimoto, T. Ishikawa, Measurements of fiber bundle interfacial properties of three-dimensionally reinforced carbon/carbon composites up to $2273 \mathrm{~K}$, Carbon 45 (2) (2007) 459-467. DOI: 10.1016/j.carbon.2006.07.028.

[18] E. Menessier, J.-P. Dumont, A. Guette, R. Pailler, L. Rabardel, R. R. Naslain, Axial and radial coefficients of thermal expansion of carbon fibers in the $20-430^{\circ} \mathrm{C}$ temperature range as derived from the thermal expansion of $1 D-$ $\mathrm{C} / \mathrm{SiO}_{2}\left(\mathrm{~B}_{2} \mathrm{O}_{3}\right)$ composites, Ceram. Eng. \& Sci. Procs. 10 (9-10) (1989) 1426 -1439. DOI:10.1002/9780470310588.ch56.

[19] S. Kawabata, Measurement of the transverse mechanical properties of highperformance fibres, The Journal of The Textile Institute 81 (4) (1990) 432447. DOI:10.1080/00405009008658721.

[20] The Toray Carbon Fiber company, M40 carbon fiber properties specifications, Datasheet (2015).

[21] M. Sakai, R. Matsuyama, T. Miyajima, The pull-out and failure of a fiber bundle in a carbon fiber reinforced carbon matrix composite, Carbon 38 (15) (2000) 2123 - 2131. DOI: 10.1016/S0008-6223(00)00067-1.

[22] H. Hatta, K. Goto, S. Ikegaki, I. Kawahara, M. S. Aly-Hassan, H. Hamada, Tensile strength and fiber/matrix interfacial properties of 2D- and 3Dcarbon/carbon composites, J. Europ. Ceram. Soc. 25 (4) (2005) 535 - 542. DOI: 10.1016/j.jeurceramsoc.2004.02.014. 
[23] T. Aoki, K. Goto, T. Ogasawara, H. Hatta, Measurements of fiber/matrix interfacial properties of a UD-C/C composite up to 2273 K, in: K. Kageyama, T. Ishikawa, N. Takeda, M. Hojo, S. Sugimoto, T. Ogasawara (Eds.), Procs. $16^{\text {th }}$ International Conference on Composite Materials, ICCM 2007, no. WeHM1-06, JSCM, Tokyo, Japan, 2007, pp. 1 - 9.

[24] R. Sharma, P. Mahajan, R. K. Mittal, Fiber bundle push-out test and imagebased finite element simulation for 3D carbon/carbon composites, Carbon 50 (8) (2012) 2717 - 2725. DOI: 10.1016/j.carbon.2012.02.030.

[25] R. Sharma, V. V. Deshpande, A. R. Bhagat, P. Mahajan, R. K. Mittal, X-ray tomographical observations of cracks and voids in 3D carbon/carbon composites, Carbon 60 (2013) 335 — 345. DOI: 10.1016/j.carbon.2013.04.046.

[26] R. Sharma, P. Mahajan, R. K. Mittal, Image Based Finite Element Analysis of 3D-Orthogonal Carbon-Carbon (C/C) Composite, in: S. I. Ao, L. Gelman, D. W. L. Hukins, A. Hunter, A. M. Korsunsky (Eds.), Procs. of the World Congress on Engineering, Vol. 2, IAEng, IAEng, London, 2010, pp. 1597 1601. ISBN: 978-988-18210-7-2.

http://www . iaeng.org/publication/WCE2010/WCE2010_pp1597-1601.pdf

[27] R. Sharma, P. Mahajan, R. K. Mittal, Elastic modulus of 3D carbon/carbon composite using image-based finite element simulations and experiments, Composite Structures 98 (2013) 69 - 78. DOI: 10.1016/j.compstruct.2012.11.019.

[28] J. R. Shewchuk, Delaunay refinement algorithms for triangular mesh generation, Comput. Geom. 22 (2002) 21-74. DOI: 10.1016/S09257721(01)00047-5. 
[29] H. Si, Constrained Delaunay tetrahedral mesh generation and refinement, Finite Elements in Analysis and Design 46 (1) (2010) 33 - 46, mesh Generation - Applications and Adaptation. DOI:10.1016/j.finel.2009.06.017.

[30] A. Gillard, M. Thévenot, S. Jouannigot, O. Caty, G. L. Vignoles, S. Chupin, G. Couégnat, Mechanical characterization of micro- and meso-scale interfaces of a 3D C/C composite, in: Procs. ECCM17-17 th European Conference on Composite Materials, Munich, Germany, 2016. ISBN: 978-300053387-7.

[31] A. Gillard, Caractérisation et modélisation du comportement thermomécanique d'un composite 3D carbone/carbone [Characterization and modeling of the thermomechanical behavior of a 3D Carbon/Carbon composite], Ph.D. thesis, University of Bordeaux (2017).

[32] G. Alfano, S. Marfia, E. Sacco, A cohesive damage-friction interface model accounting for water pressure on crack propagation, Computer Methods in Applied Mechanics and Engineering 196 (1) (2006) 192 - 209. DOI:10.1016/j.cma.2006.03.001.

[33] R. Serpieri, G. Alfano, E. Sacco, A mixed-mode cohesive-zone model accounting for finite dilation and asperity degradation, International Journal of Solids and Structures 67 (2015) 102 - 115. DOI:10.1016/j.ijsolstr.2015.04.005.

[34] R. Serpieri, E. Sacco, G. Alfano, A thermodynamically consistent derivation of a frictional-damage cohesive-zone model with different mode I and mode II fracture energies, European Journal of Mechanics Solids 49 (2015) 13-25. DOI:10.1016/j.euromechsol.2014.06.006.

[35] F. Parrinello, B. Falla, G. Borino, Cohesive-frictional interface constitutive 
model, International Journal of Solids and Structures 46 (13) (2009) 2680 2692. DOI:10.1016/j.ijsolstr.2009.02.016.

[36] D. H. Pahr, P. K. Zysset, Influence of boundary conditions on computed apparent elastic properties of cancellous bone, Biomech. Model. Mechanobiol. 7 (2008) 463 - 476. DOI: 10.1007/s10237-007-0109-7.

[37] C. Crestia, S. Calloch, A. Cosculluela, F. Hild, D. Marquis, Identification of the damage and failure mechanisms of a 3D carbon-carbon composite under uniaxial loading, in: T. Massard, A. Vautrin (Eds.), Procs. ICCM12 - 12th Intl. Conf. on Composite Materials, no. 1098, Woodhead Publishing, 1999, pp. $1-10$.

http://www. iccm-central.org/Proceedings/ICCM12proceedings/site/papers/pap1098.pdf

[38] C. Cluzel, P. Ladevèze, 4D carbon/carbon composite materials, Compos. Sci. Technol. 58 (1998) 701-708. DOI: 10.1016/S0266-3538(97)00181-4.

[39] P. Ladevèze, L. Guitard, L. Chapaney, X. Aubard, Debond modeling for multidirectional composites, Comput. Meth. Appl. Mech. Eng. 185 (2-4) (2000) 109-122. DOI: 10.1016/S0045-7825(99)00254-6.

[40] X. Aubard, C. Cluzel, L. Guitard, P. Ladeveze, Damage modeling at two scales for 4D carbon/carbon composites, Computers \& Structures 78 (1-3) (2000) 83-91. DOI: 10.1016/S0045-7949(00)00101-2.

[41] A. Este, B. Toson, J. Saliba, J. E. Yagoubi, S. Morel, E. Martin, Numerical and experimental analysis of a 3D carbon/carbon composite under fourpoint bending, in: ICACC '17: 41st International Conference on Advanced Ceramics and Composites, Daytona Beach, FL, The American Ceramic Society, 2017. 